\title{
The Inhibitive Effect of 3-Methyl 4-Amino 1,2,4 Triazole on the Corrosion of Copper-Nickel 70 - 30 in $\mathrm{NaCl} \mathrm{3 \%}$ Solution
}

\author{
Tayeb Chieb $^{1,2}$, Kamel Belmokre ${ }^{2}$, Mohammed Benmessaoud ${ }^{1,3}$, Sidi El Hassane Drissi ${ }^{3}$, Najat Hajjaji ${ }^{1}$, \\ Abdellah Srhiri ${ }^{1}$ \\ ${ }^{1}$ Laboratory of Electrochemistry, Materials and Environment (LEME), Faculty of Science, Ibn Tofail University, Kenitra, Morocco; \\ ${ }^{2}$ Laboratory Corrosion and Surface Treatment (LCST), University of Skikda, Faculty of Sciences, Skikda, Algeria; ${ }^{3}$ University of \\ Mohammed V Agdal, Energy Systems Laboratory, Materials and Environment, High School of Technology, Salé Medina, \\ Morocco. \\ Email: chiebtayeb2003@yahoo.fr
}

Received May $3^{\text {rd }}, 2011$; revised May $26^{\text {th }}, 2011$; accepted June $11^{\text {th }}, 2011$.

\begin{abstract}
The effect of 3-methyl 4-amino 1,2,4 triazole (MATA) on the corrosion behaviour of copper-nickel 70 - 30 (Monel) in $\mathrm{NaCl} 3 \%$ solution is investigated at $298 \mathrm{~K}$ by weight loss measurements, potentiodynamic polarisation and impedance spectroscopy (EIS) methods. Preliminary screening of the inhibition efficiency $\left(E_{C R}\right)$ was carried out with using weightloss measurements. Polarization measurements showed that the organic compound investigated is mixed type inhibitor (it acts on the cathodic and the cathodic reactions), inhibiting the corrosion of Monel by blocking the active sites of the metal surface. Changes in the impedance parameters charge transfer resistance $\left(R_{c t}\right)$ and double layer capacitance $\left(C_{d l}\right)$ are related to adsorption of organic inhibitor of the metal surface, leading to the formation of protective film, which grows with increasing exposure time. Inhibition efficiencies obtained from cathodic Tafel plots, gravimetric and EIS methods are in good agreement. Results obtained shows that the (MATA) is good inhibitor for copper - nickel, and its efficiency reaches more than $95 \%$ at 60 ppm after $30 \mathrm{mn}$ of immersion.
\end{abstract}

Keywords: Copper-Nickel, Triazole, Inhibitor, Efficiency, Polarisation, Impedance

\section{Introduction}

Copper and its alloys are widely used in industry because of their excellent electrical and thermal conductivity and their corrosion resistance; copper alloys are often used in heating and cooling system [1-3]. Copper-nickel 70 - 30 (Monel) has been widely used as tubing material condensers and heat exchangers in various water cooling systems [4-9]. However, the presence of certain pollutants such as sulphurs and ammonia compromise their corrosion resistance especially in sea water. Sure enough, Macdonald et al. [10,11] studied the impact of sulphur on the corrosion behaviour of copper nickel in airless sea water, these authors showed that sulphurs increases corrosion rates. On the other hand Syrett et al. [12] noticed that the sulphurs are not dangerous in the absence of oxygen. Other authors $[13,14]$ investigated the effect of ammonia, they have observed that the presence of am- monia favour the selective corrosion of copper nickel alloys by the formation of complexes compounds with copper. Sure enough, copper complexes which formed with ammonia molecules destabilize easily corrosion products layer which generally protect copper alloys [15]. During more then thirty years ago, many techniques have been used to minimise corrosion of copper-nickel. One of the techniques used for minimising corrosion is the use of inhibitors. The effectiveness of the inhibitors va- ries with its concentration, the corrosive medium and the surface properties of the alloy. Many inhibitors have been tested to minimise the corrosion of Monel in different media [16]. Particularly, heterocyclic organic compounds containing nitrogen, sulphur and/or oxygen are often used to protect metals from corrosion. Among them, azoles have been intensively investigated as effective copper corrosion inhibitors [17-20]. Benzotriazole (BTA), for example, has been studied and found to have excel- 
lent inhibition properties in several corrosive environments [21-25]. This molecule contains nitrogen atoms and has been found useful in preventing copper staining and tarnishing. The effectiveness of BTA has been related to the formation of a $\left[\mathrm{Cu}^{+}-\mathrm{BTA}^{-}\right]_{\mathrm{n}}$ film, the film formed is considered to be insoluble and polymeric [26]. Bag et al. [27] investigated the protective action of azoles on the corrosion of $70-30$ brass in ammonia solution and concluded that the inhibitors could control corrosion effectively. Shukla and Pitre [28] studied the electrochemical behaviour of brass and the inhibitive effect of imidazole in acid solution. Walker [29] showed that the addition of small amounts of the 1,1,3 benzotriazole and $1,2,4$ triazole inhibited the corrosion of brass in various acidic, neutral and alkaline solutions. Fenelon and Brezlin [30] studied the formation of BTA films on copper, $\mathrm{Cu}-\mathrm{Zn}$ alloys and $\mathrm{Zn}$ in chloride solution. Aramaki et al. [31] proposed mechanisms of benzotriazole derivatives on copper in sulphate solution at several values of $\mathrm{pH}$ by an impedance technique and enhanced Raman scattering spectroscopy. Subramanian and Lakshimina- rayanan [32] studied the adsorption properties and the effect of some azoles such as benzotriazole, mercaptobenzotriazole, benzimidazole, imidazole and tetrazole on the growth of oxide film on copper in $0.1 \mathrm{M} \mathrm{NaOH}$. All these compounds contain nitrogen and/or sulphur atoms which can co-ordinate with copper through the lone pair of electrons to form complexes. These complexes are generally believed to be polymeric in nature and form a protective film on the copper surface, which acts as a barrier of oxide film formation. The inhibitor action of these azoles may also be due to physisorption or chimisorption onto the copper surface. Trachli et al. [33] studied the protecttive effect of electropolymerized aminotriazole towards corrosion of copper in $0.54 \mathrm{M} \mathrm{NaCl}$ solution. Nagiub and Mansfeld [34] investigated the corrosion behaviour of 26,000 brasses in artificial sea water using EIS and ENA techniques. BTA, gluconic acid sodium salt and polyphosphoric acid sodium salt were evaluated as corrosion inhibitors. Qafsaoui et al. [35] studied the quantitative characterization of protective film developed on copper by anodic polarization in a borate buffered solution containing benzotriazole and aminotriazole. Al-kharafi and Ateya [36] investigated the effect of sulphides on the electrochemical impedance of copper in benzotriazoleinhibited media. Tommesani [37] studied protective action of 1,2,3-benzotriazole derivative films against copper corrosion. Although there is an extensive literature on the corrosion properties of triazole such as imidazole and benzotriazole on steel and copper, there remains little information on the effect of various functional groups in the BTA derivatives on the corrosion of copper nickel alloys. Based on this, the inhibitors have been considered and synthesized according to the previous report. In the present investigation, it is proposed to study the electrochemical behaviour of copper nickel $70-30$ in artificial seawater with 3-Methyl 4-Amino 1,2,4 triazole (MATA). Weight-loss method and electrochemical studies such as potentiodynamic polarization, impedance spectroscopy. Solution analysis was carried out to find out the concentration of $\mathrm{Cu}$ and $\mathrm{Ni}$ leached out from the copper nickel alloy using atomic absorption spectroscopy.

\section{Experimental Conditions}

Monel strips having chemical compositions (wt $\%$ ): 69.3\% $\mathrm{Cu}, 29.6 \% \mathrm{Ni}, 0.7 \% \mathrm{Mn}, 0.4 \% \mathrm{Fe}$. The $\mathrm{NaCl} 3 \%$ solution was prepared by dissolving $30 \mathrm{~g}$ of pure $\mathrm{NaCl}$ in 11 of distilled water. The inhibitor: 3-Methyl 4-Amino 1,2,4 triazole (MATA) was synthesized according to the reported procedures [38] and its structure is shown in Figure 1.

Weight-loss method measurements were performed with rectangular Monel coupons $(5 \mathrm{~cm} \times 3 \mathrm{~cm} \times 0.3 \mathrm{~cm})$. The coupons were immersed in $300 \mathrm{ml}$ of $\mathrm{NaCl} 3 \%$ solution with and without inhibitors and allowed to for 5 days at room temperature $\left(25^{\circ} \mathrm{C}\right)$. Afterwards, the coupons were rinsed with distilled water and adherent corrosion products were removed by immersing the coupons in $6 \%$ $\mathrm{H}_{2} \mathrm{SO}_{4}$ for $20 \mathrm{~s}$. Then the coupons were rinsed with distilled water, cleaned with acetone, dried and weighed. Duplicate tests were conducted with for each experiment.

The corrosion rate $C R$ and the percentage of inhibition efficiency $E_{C R}(\%)$ over the exposure period were calculated using the following equations [39]:

$$
\begin{gathered}
C R=\frac{87.6 \times W}{D \times A \times T} \\
E_{C R}(\%)=\frac{C R-C R_{\text {inh }}}{C R} \times 100
\end{gathered}
$$

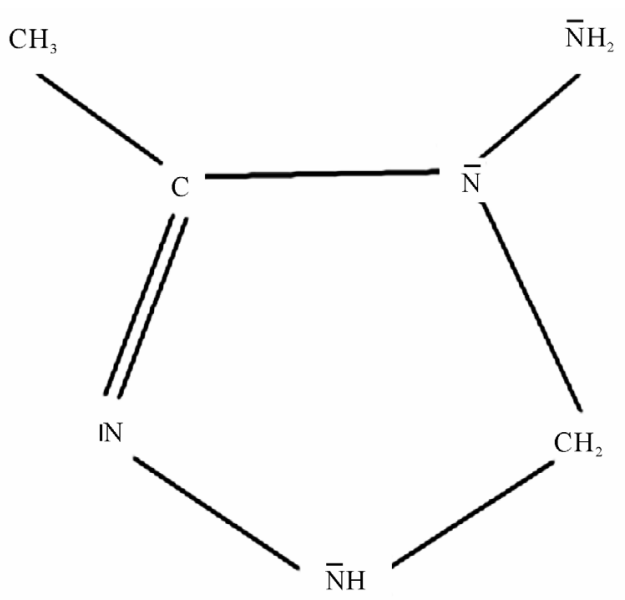

Figure 1. 3-Methyl 4-Amino 1,2,4 triazole (MATA). 
where $W$ is the weight-loss in (mg), $T$ the immersion time in (hours), $A$ the coupons area in $\left(\mathrm{cm}^{2}\right), D$ the density of the specimen in $\left(\mathrm{g} / \mathrm{cm}^{3}\right), C R_{\text {inh }}$ and $C R$ are the corrosion rate of Monel in the presence and absence of inhibitor respectively.

The potentiodynamic polarization studies were carried out with Monel strips having an exposed surface area of $1 \mathrm{~cm}^{2}$. The electrodes were abraded mechanically with silicon carbide papers from 120 to 1200 grit, the electrode was thoroughly washed with distilled water, degreased in acetone, rinsed with distilled water and dried. The cell assembly consisted of Monel as working electrode, a platinum foil as counter electrode and $\mathrm{Ag} / \mathrm{AgCl}$ as reference electrode (RE). Polarization studies were carried out using potentiostat/galvanostat (model PGZ 201). The working electrode was immersed in aerated $\mathrm{NaCl} 3 \%$ solution and allowed to stabilize for $30 \mathrm{~min}$ [40]. The cathodic and anodic polarization curves for Monel specimen in the test solution with and without inhibitors were recorded at a scan rate of $1 \mathrm{mv} / \mathrm{s}$. The inhibition efficiency of MATA was determined from corrosion current density using the Tafel extrapolation method.

Electrochemical impedance spectra (EIS) were carried out at $\mathrm{E}_{\text {corr }}$ using an electrochemical system response analyser (model EGG). Monel with the exposed surface of $1 \mathrm{~cm}^{2}$ was used as the working electrode. A conventional three-electrode electrochemical cell of volume 300 $\mathrm{ml}$ was used. The reference electrode is on $\mathrm{Ag} / \mathrm{AgCl}$, the platinum plate electrode was used as the counter. The EIS were acquired in the frequency range from $100 \mathrm{kHz}$ to $1 \mathrm{mHz}$ with $10 \mathrm{mV}$ amplitude sine wave generated by a frequency response analyser.

After the polarization measurements, the solutions were analysed by atomic absorption spectroscopy to measure the amount of $\mathrm{Cu}$ and $\mathrm{Ni}$ leached out from the Monel samples at the optimum concentration of inhibitor. The denickelification factor $(f)$ is calculated using the relation.

$$
f=\frac{(\mathrm{Ni} / \mathrm{Cu})_{\text {sol }}}{(\mathrm{Ni} / \mathrm{Cu})_{\text {alloy }}},
$$

where the ratio $(\mathrm{Ni} / \mathrm{Cu})_{\text {sol }}$ is determined from the solution analysis and $(\mathrm{Ni} / \mathrm{Cu})_{\text {alloy }}$ is the weight-percent ratio of the elements in the alloy.

\section{Results and Discussion}

\subsection{Weight-Loss Method}

Table 1 Show the corrosion rate and inhibition efficiency of Monel by weight-loss measurements at different concentrations of inhibitor in $\mathrm{NaCl} 3 \%$ solution at room tem-
Table 1. Inhibition efficiency for various concentration of (MATA) for the corrosion of Monel in $\mathrm{NaCl} \mathrm{3 \%}$ solution obtained by weight-loss method.

\begin{tabular}{ccc}
\hline [Inhibitor] (ppm) & $\mathbf{C R}\left(\times \mathbf{1 0}^{-\mathbf{2}} \mathbf{~} \mathbf{m m} \cdot \mathbf{y e a r}^{-\mathbf{1}}\right)$ & $\boldsymbol{E}_{\mathbf{C R}} \mathbf{( \% )}$ \\
\hline Blank & 25.5 & - \\
20 & 7.65 & 70.0 \\
40 & 3.83 & 84.9 \\
60 & 1.28 & 95.0 \\
80 & 2.8 & 89 \\
100 & 3.8 & 85 \\
\hline
\end{tabular}

perature $\left(25^{\circ} \mathrm{C}\right)$. The results showed that the corrosion rate of Monel decreased whereas the inhibition efficiency increased with increasing inhibitor concentration. The maximum E\% of the inhibitor (MATA) was achieved at $60 \mathrm{ppm}$ and a further increase in concentration showed a decrease of inhibitor efficiency. Hence, the optimum concentration of the inhibitor was found to be $60 \mathrm{ppm}$.

It is well known that the inhibitive action of organic compounds containing $\mathrm{N}$, and/or $\mathrm{S}$, are due to the formation of co-ordinate type of bond between the metal and the lone pair of electrons present in the additive. The tendency to form co-ordinate bond and hence the extent of inhibition can be enhanced by increasing the effective electron density at the functional group of the additive, in aromatic or heterocyclic ring compounds, the effective electron density at the functional group can be varied by introducing different substituent in the ring leading to variations of the molecular structure.

The inhibition efficiency of triazolic derivates compounds is due to donor-acceptor interactions between the $\pi$ electrons of the inhibitor and the vacant d-orbital of copper surface or an interaction of inhibitor with already adsorbed chloride ions [41]. Based on the results, the organic compound (MATA) showed good performance in $\mathrm{NaCl} 3 \%$ solution. The high solubility of 3-methyl 4-amino 1,2,4 triazole in the corrosive media and the presence of $\mathrm{NH}_{2}$ group and $\mathrm{CH}_{3}$ radical allow the compound to inhibit the metal surface in tandem.

\subsection{Potentiodynamic Polarization Studies}

The cathodic and anodic polarization curves of Monel in $\mathrm{NaCl} 3 \%$ solution with varying concentrations of MATA are shown in Figures 2 and 3. The three distinct regions appearing in the anodic polarization curve were the active dissolution region (apparent Tafel region), the active-to-passive transition region and the limiting current region. 


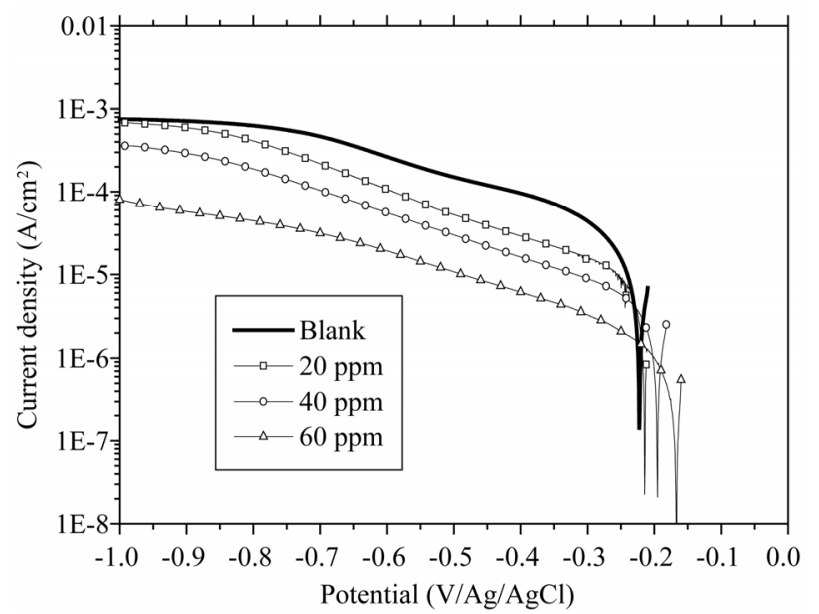

Figure 2. Cathodic polarization curves of Monel in aerated $3 \% \mathrm{NaCl}$ without and with various concentrations of MATA at $25^{\circ} \mathrm{C}: \Omega=1000 \mathrm{rpm} ;|\mathrm{dE} / \mathrm{dt}|=1 \mathrm{~m} \cdot \mathrm{Vs}^{-1}$.

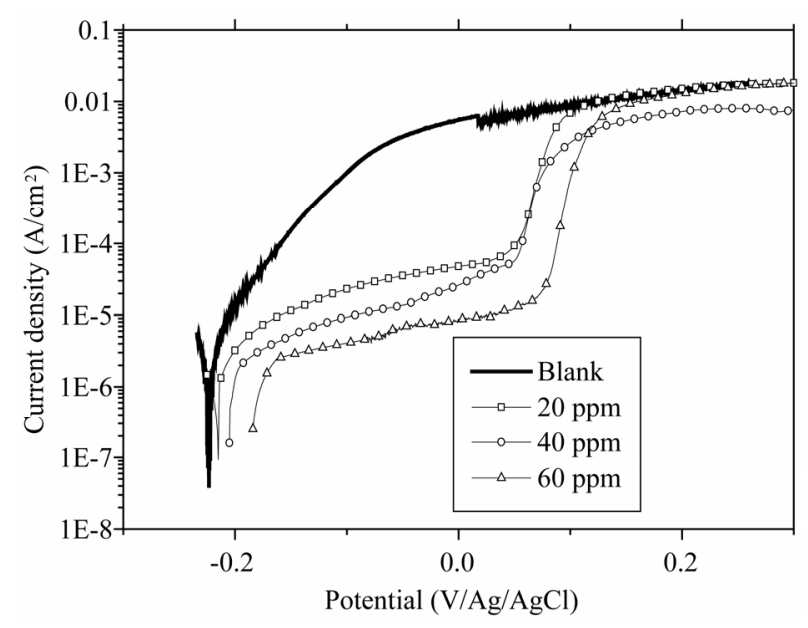

Figure 3. Anodic polarization curves of Monel in aerated $3 \% \mathrm{NaCl}$ without and with various concentrations of MATA at $25^{\circ} \mathrm{C}: \Omega=1000 \mathrm{rpm} ;|\mathrm{dE} / \mathrm{dt}|=1 \mathrm{~m} \cdot \mathrm{Vs}^{-1}$.

It is evident that in the presence of inhibitor, the cathodic and anodic curves were shifted towards positive region and the shift was found to be dependent on inhibitor concentration. The Table 2 illustrates the corresponding electrochemical parameters. The $\mathrm{E}_{\text {corr }}$ were marginally shifted in the presence of MATA. This observation clearly indicated that the inhibitor control the anodic and cathodic reaction and thus act as mixed type inhibitor. The current density also decreased with increasing concentration of inhibitor. The corrosion rates [42] and the inhibition efficiency [43] were calculated from polarization curves using the following equations:

$$
C R=\frac{3.27 \times E w \times I_{\text {corr }} \times 10^{-3}}{D}
$$

Table 2. Polarisation parameters and corresponding inh ibition efficiency for the corrosion of cupper-nickel 70 30 in $\mathrm{NaCl} 3 \%$ without and with addition of various $\mathrm{c}$ oncentration of inhibitor.

\begin{tabular}{ccccc}
\hline Solution & Blank & $20 \mathrm{ppm}$ & $40 \mathrm{ppm}$ & $60 \mathrm{ppm}$ \\
\hline $\boldsymbol{b}_{\boldsymbol{c}}(\mathbf{m V} / \mathbf{d e c})$ & -288 & -238 & -218 & -196 \\
$\boldsymbol{E}_{\text {corr }}(\mathbf{m V} / \mathbf{A g} / \mathbf{A g C l})$ & -222 & -214 & -195 & -167 \\
$\boldsymbol{i}_{\text {corr }}\left(\boldsymbol{\mu} \mathbf{A} \cdot \mathbf{c m}^{-2}\right)$ & 24.5 & 6.92 & 3.28 & 0.8 \\
$\mathbf{C R}\left(\times \mathbf{1 0}^{-\mathbf{2}} \mathbf{~} \mathbf{m m} \cdot \mathbf{y e a r}^{-1}\right)$ & 26.00 & 7.36 & 3.49 & 0.85 \\
$\mathbf{E ~ ( \% ) ~}$ & - & 71.7 & 86.6 & 96.7 \\
\hline$E \%=\frac{I_{\text {corr }}-I_{\text {corr }(\text { inh })}}{I_{\text {corr }}} \times 100$ & &
\end{tabular}

where $\mathrm{CR}$ is the corrosion rate $\left(\mathrm{mm} \cdot \mathrm{year}^{-1}\right), \mathrm{D}$ the density $\left(\mathrm{g} \cdot \mathrm{cm}^{-3}\right)$, EW the equivalent weight of the specimen and $I_{\text {corr }(\text { inh })}$ and $I_{\text {corr }}$ are the corrosion current density $\left(\mu \mathrm{A} \cdot \mathrm{cm}^{-2}\right)$ values with and without inhibitor respectively.

The values of cathodic Tafel slope $\left(b_{c}\right)$ it found to change with inhibitor concentrations, indicates that inhibitor controlled both the reactions. The inhibition efficiency of MATA attained a maximum value of $96.7 \%$ at $60 \mathrm{ppm}$. The values of inhibition efficiency increase with increasing concentration of inhibitor, indicating that a higher surface coverage was obtained in a solution with the optimum concentration of inhibitor. The corrosion rate in blank solution was found to be $26 \times 10^{-2} \mathrm{~mm}$.year ${ }^{-1}$ and it was minimized by adding the inhibitor to a lower value of $0.85 \times \mathrm{mm} \cdot \mathrm{year}^{-1}$ for the Monel due to the presence of MATA on the metal surface.

\subsection{Impedance Studies}

The impedance diagrams are represented in Nyquist plot, obtained in solution with and without the MATA inhibittor, for different concentrations, are presented in Figure 4. The electrode was prepolarized at the free corrosion potential until a steady-state was attained.

The impedance spectra in the absence of MATA present one capacitive loop. In the context of a detailed study published elsewhere [44], this loop is attributed to a charge transfer process, the value of associated resistance is about $1.5 \mathrm{kOhm} \cdot \mathrm{cm}^{2}$, the capacity is in the order of $168 \mu \mathrm{F} \cdot \mathrm{cm}^{-2}$. In the presence of inhibitor, we note that the impedance display of the electrode in MATA containing the solution changes in shape and size, on the other hand it can be noticed that the impedance modulus increased dramatically in presence of inhibitor from 20 ppm of MATA. The presence of two capacitive loops seems to indicate a diffusion contribution to the beginning of the experiment. 


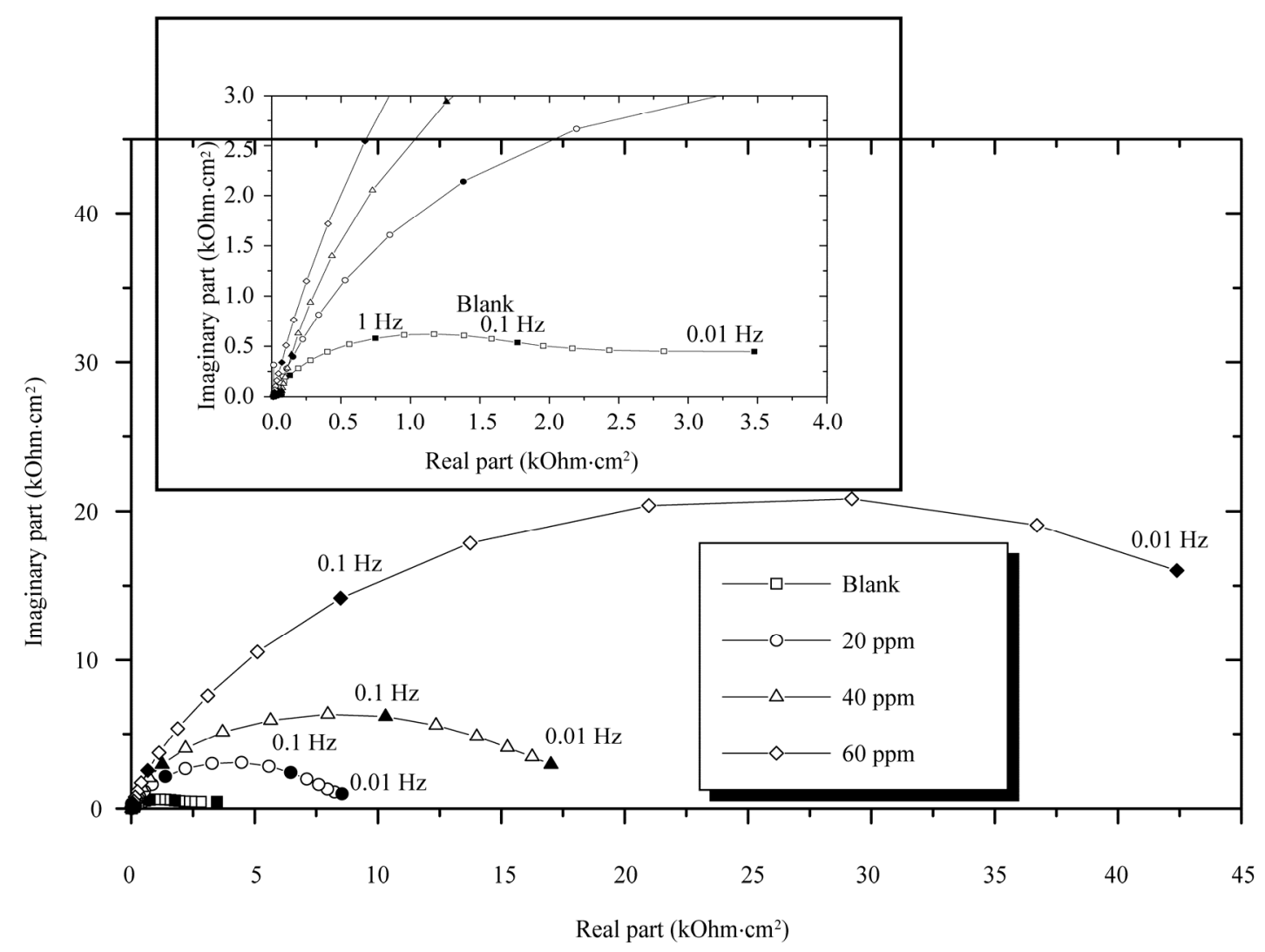

Figure 4. Nyquist plots of copper-nickel 70 - 30 in $\mathrm{NaCl} 3 \%$ with and without various concentration of inhibitor.

Figure 5 shows the impedance diagrams obtained in corrosive solution at the corrosion potential after the $\mathrm{Cu}$ $30 \mathrm{Ni}$ electrode was exposed to the solution for different immersion times. It maintains the same shape after 30 min of immersion time. As can be seen in this figure, the impedance diagrams in the Nyquist plot become larger with time.

It can be seen that $\mathrm{Rt}$ and $\mathrm{Cd}$ increased with time. The increase of Rt may be explained by the formation of copper chloride which protects the copper against the corrosion. With accumulation of corrosion products, the surface roughness increased leading to a higher $\mathrm{Cd}$ value.

Figure 6 shows the impedance diagrams obtained in corrosive solution at $60 \mathrm{ppm}$ of MATA at the corrosion potential after the Monel electrode was exposed to the solution for different immersion times. It maintains the same shape after $30 \mathrm{~min}$ of immersion time. As can be seen in this figure, the impedance diagrams in the $\mathrm{Ny}$ quist plot become larger with time. The increase of the polarisation resistance with the immersion period is often reported for the inhibiting action of heterocyclic on copper corrosion. At $30 \mathrm{~min}$ of immersion time, we have a loop in high frequencies (HF) and dispersion in low frequencies range. If we allot the HF loop to the charge transfer resistance $\mathrm{Rt}$, then associated resistance is about $42 \mathrm{kOhm} \cdot \mathrm{cm}^{2}$. The capacity is of the order $14.8 \mu \mathrm{F} \cdot \mathrm{cm}^{2}$.

The effect of increasing immersion time on impedance spectra is characterised by the increasing size of the two capacitive loops observed, reaching a maximum in $20 \mathrm{~h}$.

The percentage inhibition efficiency $(\mathrm{E} \%)$ is calculated from the charge transfer resistance values using the following equation :

$$
E \%=\frac{R_{c t}-R_{c t(i n h)}}{R_{c t}} \times 100
$$

where $R_{c t(i n h)}$ and $R_{c t}$ are the charge transfer resistance values with and without inhibitor respectively. The impedance parameters derived from these investigations are given in Tables 3 and 4. It is found that $R_{c t}$ values increased in the presence of inhibitor and with immersion time, whereas $C_{d l}$ values found to be decreased. The decrease in $C_{d l}$ values was due to the adsorption of MATA on the metal surface. The inhibition efficiency reached 88.8 and $96.3 \%$ at 40 and $60 \mathrm{ppm}$ respectively after 30 min of immersion, and it was not affected by the immersion time $(95.2 \%$ after $20 \mathrm{~h}$ in the presence of inhibitor at $60 \mathrm{ppm})$. 


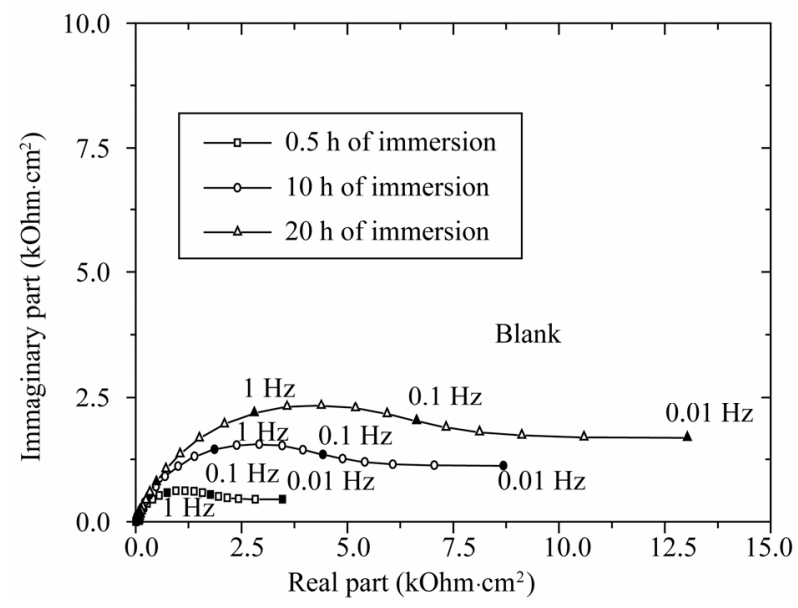

Figure 5. Nyquist plots of copper-nickel 70 - 30 in $\mathrm{NaCl} 3 \%$ after $0.5 \mathrm{~h}, 10 \mathrm{~h}$ and $20 \mathrm{~h}$ of immersion.

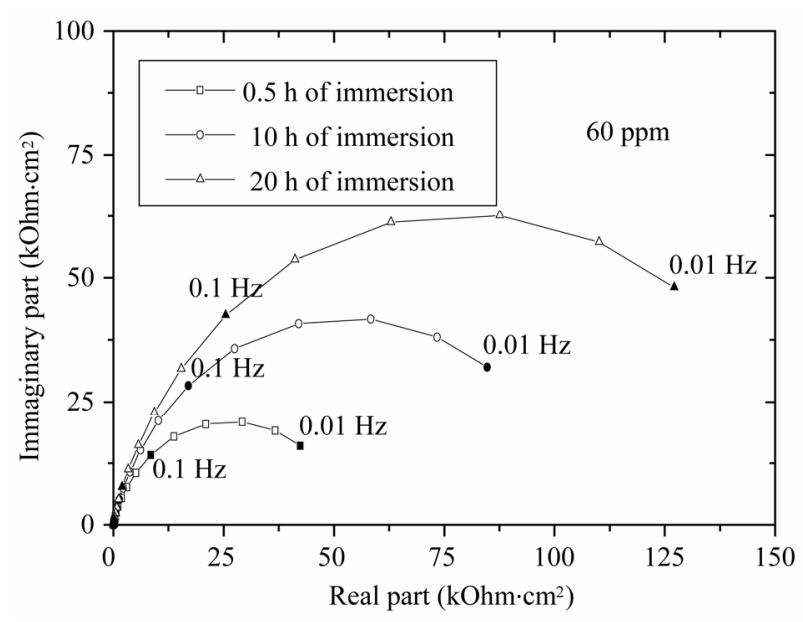

Figure 6. Nyquist plots of copper-nickel 70 - 30 in $\mathrm{NaCl} \mathrm{3 \%}$ containing optimum concentration of MATA after $0.5 \mathrm{~h}, 10$ $h$ and $20 \mathrm{~h}$ of immersion.

Table 3. Impedance parameters for the corrosion of cuppernickel 70 - 30 in $\mathrm{NaCl} \mathrm{3 \%}$ in the absence and presence of inhibitor in different concentrations.

\begin{tabular}{cccc}
\hline Concentration $(\mathbf{p p m})$ & $\boldsymbol{R}_{c t}\left(\mathbf{k} \boldsymbol{\Omega} \cdot \mathbf{c m}^{2}\right)$ & $\boldsymbol{C}_{d l}\left(\boldsymbol{\mu F \cdot \mathbf { c m } ^ { - 2 } )}\right.$ & $\mathbf{E}(\%)$ \\
\hline 0 & 1.5 & 168 & - \\
20 & 7 & 23.8 & 73.3 \\
40 & 13.50 & 18.8 & 88.8 \\
60 & 40.75 & 9.76 & 96.3 \\
\hline
\end{tabular}

\subsection{Solution Analysis}

The results of solution analysis and the corresponding denickelification factor ( $\mathrm{f}$ ) in the presence and absence of
MATA at its optimum concentration level in $\mathrm{NaCl} 3 \%$ solution for Monel are given in Table 5.

The results revealed that both copper and nickel were present in the solution. The nickel/copper ratio in solution was found to be higher than that of the bulk alloy. This indicates that the growth of surface film and the dissolution of the alloy were controlled by diffusion [45], which is related to the difference between the ionic rayon of $\mathrm{Ni}^{2+}$ and $\mathrm{Cu}^{+}$ions, $0.085 \mathrm{~nm}$ and $0.096 \mathrm{~nm}$ respectively. It is also observed that the inhibitor is able to retard the dissolution of both copper and nickel. This observation suggests that the inhibitor excellently control the denickelification of Monel in $\mathrm{NaCl} 3 \%$ solution, which is also reflected in the values of denickelification factor

\section{Conclusions}

Electrochemical study showed that MATA product tested is good inhibition efficiency for Monel in $\mathrm{NaCl} 3 \%$ solution both after a short and long immersion time. Polarization measurements showed that the organic compound investigated are mixed type inhibitor, inhibiting the corrosion of Monel by blocking the active sites of the metal surface. The inhibitor easily adsorb on the Monel surface at the corrosion potential and form a protective complex with the $\mathrm{Cu}$ (I) ion, controlling Monel from corrosion. Impedance studies showed that the change in charge transfer resistance $\left(R_{c t}\right)$ and double layer capacity $\left(C_{d l}\right)$ are related to the adsorption of organic inhibitor on the metal surface, leading to the formation of a protective

Table 4. Impedance parameters for the corrosion of cuppernickel 70 - 30 in $\mathrm{NaCl} 3 \%$ in the absence and presence of 60 ppm of MATA after different immersion times.

\begin{tabular}{ccccc}
\hline Solution & Time (h) & $\mathbf{R}_{\mathbf{t}}\left(\mathbf{k} \boldsymbol{\Omega} \cdot \mathbf{c m}^{\mathbf{2}}\right)$ & $\mathbf{C}_{\mathbf{d l}}\left(\boldsymbol{\mu F \cdot \mathbf { c m } ^ { - 2 } )}\right.$ & $\mathbf{E} \mathbf{( \% )}$ \\
\hline \multirow{3}{*}{ Blank } & $\mathbf{0 . 5}$ & 1.5 & 106 & - \\
& $\mathbf{1 0}$ & 3.8 & 92 & - \\
& $\mathbf{2 0}$ & 5.8 & 61 & - \\
60 ppm MATA & $\mathbf{1 0}$ & 81 & 4.8 & 94.6 \\
& $\mathbf{0 . 5}$ & 42 & 3.5 & 95.2 \\
\hline
\end{tabular}

Table 5. Effect of optimum concentration of MATA on the denickelification of Monel in $\mathrm{NaCl} 3 \%$ solution.

\begin{tabular}{cccccc}
\hline Solution & Cu (ppm) & Ni (ppm) & Factor (f) & Cu (\%) & Ni (\%) \\
\hline blank & 10.46 & 37.34 & 8.32 & - & - \\
$\mathbf{6 0} \mathbf{~ p p m}$ & 0.732 & 2.24 & 7.14 & 93 & 94 \\
\hline
\end{tabular}


film, which grows with increasing exposure time. Solution analysis revealed that the MATA excellently control the denickelification of monel in $\mathrm{NaCl} 3 \%$ solution.

\section{REFERENCES}

[1] E. Stupnisek-Lisac, A. Loncarich Bozich and I. Cafuk, "Low-Toxicity Copper Corrosion Inhibitors," Corrosion, Vol. 54, No. 9, 1998, Document ID 98090713.

[2] R. Gasparac, C. R. Martin and E. Stupnisek-Lisac, "In Situ Studies of Imidazole and Its Derivatives as Copper Corrosion Inhibitors. I. Activation Energies and Thermodynamics of Adsorption," Journal of the Electrochemical Society, Vol. 147, No. 2, 2000, pp. 551-548. doi:10.1149/1.1393230

[3] A. Zaki, "Electrochemical Behaviour of Copper-Silver Alloys in Sodium Carbonate Aqueous Solution," British Corrosion Journal, Vol. 36, No. 1, 2001, pp. 59-64. doi:10.1179/000705901101501505

[4] R. F. North and M. J. pryar, "The Influence of Corrosion Product on the Corrosion Rate of Cu-Ni Alloys," Journal of Corrosion Science, Vol. 10, 1970, pp. 297-311.

[5] M. A. Elmorsi, M. Y. El Sheikh, A. M. Bastweesy and M. M. Ghoneim, "Effect of Hydroxyl Compounds on Corrosion Behaviour of $\mathrm{Cu}$ and $\mathrm{Cu}-\mathrm{Zn}$ Alloys in $3 \% \mathrm{NaCl}$ Solutions," Bulletin of Electrochemistry, Vol. 7, 1991, p. 158.

[6] M. M. Osman, "Corrosion Inhibitor of Aluminum.-Brass in $3.5 \% \mathrm{NaCl}$ Solution and Sea Water," Journal of Materials Chemistry and Physics, Vol. 71, 2001, p. 12.

[7] M. A. Qureishi, I. H. Farooqi and P. A. Saini, "Inhibition of Dezincification of 70-30 Brass by Aminoalkyl Mercaptotriazoles," British Corrosion Journal, Vol. 35, No. 1, 2000, pp. 78-80.

[8] H. C. Shih and R. J. Tzou, "Effect of Benzotriazole of the Stress Corrosion Cracking and the Electrochemical Polarization of 70/30 Brass," Journal of Electrochemical Society, Vol. 138, No. 4, 1991, pp. 958-961. doi:10.1149/1.2085753

[9] G. Quartarone, G. Moretti and T. Bellami, "Using Indole to Inhibit Copper Corrosion in Aerated $0.5 \mathrm{M}$ Sulfuric Acid," Corrosion, Vol. 54, No. 8, 1998, Document ID 98080606.

[10] D. D. Macdonald, B. C. Syrett and S. S. Wing, "The Corrosion of $\mathrm{Cu}-\mathrm{Ni}$ Alloys 706 and 715 Flowing Sea Water," Corrosion, Vol. 35, No. 8, 1979, pp. 367-378.

[11] D. D. Macdonald, B. C. Syrett and S. S. Wing, "Annual Report of Naval Research," ONR Contrat, No. 00014-770046, NR 36-116, 1979.

[12] B. C. Syrett and D. D. Macdonald, "The Validity of Electrochemical Methods for Measuring Corrosion Rates of Copper-Nickel Alloys in Sea Water," Corrosion, Vol. 35, No. 11, 1979, pp. 505-509.

[13] B. Trachli, , "Etude sur la Corrosion du Cuivre en Milieu $\mathrm{NaCl} 0.5 \mathrm{M}$ et sa Protection par des Inhibiteurs Organiques et des Films Polyméres Obtenus par Électro- polymerisation," Cotutelle Thesis, P\&M Curie UniversityKénitra University, Paris-Kénitra, 2001.

[14] R. Francis, "Effect of Pollutants on Corrosion of Copper Alloys in Sea Water," British Corrosion Journal, Vol. 20, No. 4, 1985, pp. 167-173.

[15] D. A. Jones, "Principles and Prevention of Corrosion," Maxwell Macmillan Pub., New York, 1992.

[16] M. A. Elmorsi and A. M. Hassanein, "Corrosion Inhibition of Copper by Heterocyclic Compounds," Journal of Corrosion Science, Vol. 41, 1999, pp. 2337-2352.

[17] F. Ammeloot, C. Fiaud and E. M. M. Sutter, "Characterization of the Oxide Layers on a Cu-13Sn Alloy in $\mathrm{NaCl}$ Aqueous Solution without and with $0.1 \mathrm{M}$ Benzotriazole," Journal of Electrochemica Acta, Vol. 44, No. 15, 1999 , pp. 2549-2558.

[18] Y. I. Kusnetzov, "Organic Inhibitors of Corrosion of Metals," Plenum Press, New York, 1996.

[19] N. K. Patel, J. Franco and I. S. Patel, "Corrosion of 63/37 Brass in Citric Acid Solution and Its Inhibition by Azole-Type Compounds," Journal of India Chemical Society, Vol. 54, 1997, p. 815.

[20] C. W. Yan, H. C. Lin and C. N. Cao, "Investigation of Inhibition of 2-Mercaptobenzotriazole for Copper Corrosion," Journal of Electrochemica Acta, Vol. 45, No. 17, 2000, pp. 2815-2821.

[21] D. Zhang, L. Gao and G. Zhou, "Inhibition of Copper Corrosion by Bis-(-Benzotriazolmethylene)-(2,5 Thiadiazoly)-Disulfide in Chloride Media," Journal of Applied Surface Science, Vol. 225, 2004, pp. 287-293.

[22] G. Xue, G. Ding, P. Lu and J. Dong, "SERS, XPS, and Electrochemical Studies of the Chemisorption of Benzotriazole on a Freshly Etched Surface and an Oxidized Surface of Copper," Journal of Physical and Chemistry, Vol. 95, 1991, pp. 7380-7384.

[23] N. Bellakhal and M. Dechraoui, "Study of Benzotriazole Efficiency as Corrosion Inhibitor of Copper in Humid Air Plasma," Journal of Materials Chemistry and Physics, Vol. 85, No. 2-3, 2004, pp. 366-369.

[24] R. Yuda, H. Nishihara and K. Aramaki, “A SERS Study on Inhibition Mechanisms of Benzotriazole and Its Derivates for Copper Corrosion in Sulfate Solutions," Journal of Corrosion Science, Vol. 28, No. 1, 1998, pp. 87-96.

[25] J. Bukowska and A. Kudelski, "The Use of Surface Enhanced Raman Scatting (SERS) to Probe the Interaction of Imidazole with the Silver Electrode Surface," Journal of Electroanalytical Chemistry and Interfacial Chemistry, Vol. 309, No. 1-2, 1991, pp. 251-261.

[26] D. Tromans and J. C. Silva, "The Anodic Behaviour of Copper in Chloride/Tolyltriazole and Chloride Benzotriazole Solution," Journal of Corrosion, Vol. 53, 1997, pp. 16-25.

[27] S.K Bag, S. B. Shakraborty, A. Roy and S. R. Chaudhury, "2-Aminobenzimidazole as Corrosion Inhibitor for 70-30 Brass in Ammonia," British Corrosion Journal, Vol. 31, No. 3, 1996, pp. 207-212. 
[28] J. Shukla and K. S. Pitre, "Electrochemical Behavior of Brass in Acid Solutions and the Inhibitive Effect of Imidazole," Corrosion Reviews, Vol. 20, No. 3, 2002, pp. 217-229.

[29] R. Walker, "Aqueous Corrosion of Tin-Bronze and Inhibition by Benzotriazole," Corrosion, Vol. 56, No. 12, 2000, pp. 1211-1219.

[30] A. M. Fenelon and C. B. Brezlin, "An Electrochemical Study of the Formation of Benzotriazole Surface Films on Copper, Zinc and Copper-Zinc Alloy," Journal of Applied Electrochemistry, Vol. 31, No. 5, 2001, pp. 509-516. doi:10.1023/A:1017503031045

[31] K. Aramaki, T. Kiuchi, T. Simuyoshi and H. Nishihara, "Surface Enhanced RAMAN Scattering and Impedance Studies on the Inhibition of Copper Corrosion in Sulfate Solution by 5-Substituted Benzotriazoles," Journal of Corrosion Science, Vol. 32, No. 5-6, 1991, pp. 593-607.

[32] R. Subramanian and V. Lakshiminarayanan, "Effect of Adsorption of Some Azoles on Copper Passivation in Alkaline Medium," Journal of Corrosion Science, Vol. 44, No. 3, 2002, pp. 535-554.

[33] B. Trachli, M. Keddam, H. Takenouti and A. Srhiri, "Protective Effect of Electropolymerized 3-Amino-1,2,4Triazole towards Corrosion of Copper in $0.5 \mathrm{M} \mathrm{NaCl}$ Solution," Journal of Corrosion Science, Vol. 44, No. 5, 2002, pp. 997-1008.

[34] A. Nagiub and F. Mansfeld, "Evaluation of Corrosion Inhibition of Brass in Chloride Media Using EIS and ENA," Journal of Corrosion Science, Vol. 43, No. 11, 2001, pp. 2147-2171.

[35] W. Qafsaoui, C. Blanc, N. Pebere, H. Takenouti, A. Srhiri and G. Mankowski, "Quantitative Characterization of Protective Films Grown on Copper in the Presence of Different Triazole Derivative Inhibitors," Journal of Electrochemica Acta, Vol. 47, No. 27, 2002, pp. 4339-4345.

[36] F. M. El-Kharafi and B. G. Ateya, "Effect of Sulfides on the Electrochemical Impedance of Copper in Benzotriazole-Inhibited Media," Journal of the Electrochemical Society, Vol. 149, No. 6, 2002, pp. B206-B210.

\section{doi:10.1149/1.1470656}

[37] L. Tommesani, G. Brunoro, A. Fringnani, C. Monticelli and M. Dal Colle, "On the Protective Action of 1, 2, 3 Benzotriazole Derivative Films against Copper Corrosion," Journal of Corrosion Science, Vol. 39, No. 7, 1997, pp. 1221-1237.

[38] A. R. katritzky, S. Rachwal and B. Rachwal, "The Chemistry of Benzotriazole. Part 3. The Aminoalkylation of Benzotriazole," Journal of the Chemical Society, Perkin Transactions, Vol. 1, 1987, pp. 799-804.

[39] M. G. Fontana, "Corrosion Engineering," 3rd Edition, McGraw-Hill Book Company, New York, 1987.

[40] G. Petrova, E. Sokolova, S. Raicheva and P. Ivanov, "Inhibition of Copper Corrosion in a Simulated Cooling Water by Pyrophthalone Compounds," British Corrosion Journal, Vol. 31, No. 1, 1996, pp. 55-60.

[41] N. Hackemen, E. S. Snavelly and J. S. Payne, "Effects of Anions on Corrosion Inhibition by Organic Compound," Journal of Electrochemical Society, Vol. 113, No. 7, 1966, pp. 677-681. doi:10.1149/1.2424089

[42] R. G. Lakshmi, "Electrochemical and Wear Behaviour of Surface Modified Orthopaedic Titanium Alloys," Ph.D. Thesis, Anna University, India, 2003.

[43] B. Ramesh Babou and R. Holz, "Corrosion and Hydrogen Permeation Inhibition for Mild Steel in $\mathrm{HCl}$ by Isomers of Organic Compounds," British Corrosion Journal, Vol. 35, No. 3, 2000, pp. 204-209. doi: $10.1179 / 000705900101501254$

[44] K. Es-Salah, F. Said, M. Benmessoud, N. Hajjaji, M. Aouial, H. Takenouti and A. Srhiri, "Corrosion of Copper-Nickel (Cu-30Ni) Alloy in 3\% $\mathrm{NaCl}$ Solution, in Presence of Ammoniac to pH 9, 25: The Inhibition Effect of the Bitriazole (BITA)," Physical Chemical News, Vol. 23, 2005, pp. 108-118.

[45] W. J. Van Oojj, "Surface Composition, Oxidation and Sulfidation of Cold-Worked Brass and Brass-Coated Steel Wire as Studied by X-Ray Photoelectron Spectroscopy I. Surface Composition of Commercial ColdWorked Brass," Surface Technology, Vol. 6, No. 1, 1977, pp. 1-18. doi:10.1016/0376-4583(77)90019-X 